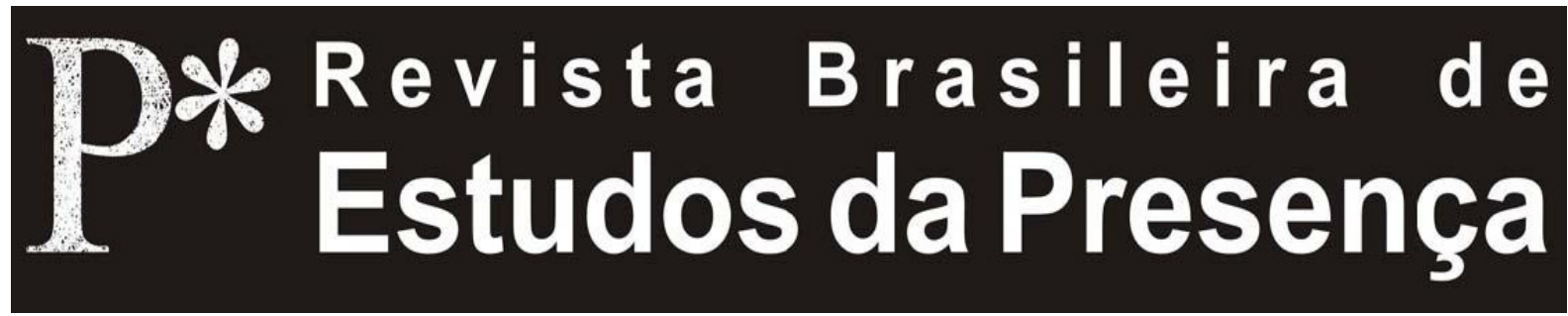

DOI - http://dx.doi.org/10.1590/2237-266037294

ISSN 2237-2660

\title{
A Estética da Pan Pan Theatre
}

\author{
Noelia Ruiz \\ University College Dublin - Dublin, Irlanda
}

RESUMO - A Estética da Pan Pan Theatre - Este artigo visa elucidar a estética da Pan Pan Theatre através de uma instância do seu processo de ensaio, especialmente nos termos de seu tipo de performance, que não pode ser dissociado de sua intençáo manifesta de criar uma atmosfera bastante específica. Para tal, o texto explora o continuum de Michael Kirby entre a performance não-matricial e a atuação complexa, assim como conceito de Lehmann sobre o tempo e espaço como metonímicos.

Palavras-chave: Teatro Contemporâneo. Teatro Pós-Dramático. Processos Criativos. Análise de Companhia. Genética da Performance.

ABSTRACT - Pan Pan Theatre Aesthetics - This paper aims to elucidate Pan Pan Theatre's aesthetics through an instance of their rehearsal process, especially in terms of their performance mode, which cannot be dissociated from their manifest intention to create a specific atmosphere. This paper explores Michael Kirby's continuum between non-matrixed performance and complex acting, with regard to Pan Pan Theatre's performance style, which enhances a particular conception of time and space as metonymic.

Keywords: Contemporary Theatre. Postdramatic Theatre. Creative Processes. Company Analysis. Genetics of Performance.

RÉSUMÉ - L'Esthétique de la Compagnie Pan Pan Théâtre - Cet article cherche à appréhender l'esthétique de la compagnie Pan Pan Théâtre à partir de l'observation de son processus de création. Il s'attache plus particulièrement à son type de performance qui ne peut pas être dissocié d'une intention manifeste de créer une atmosphère assez particulière. Pour ce faire, l'auteur explore le continuum de Michael Kirby, entre la performance non matricielle et le jeu complexe, ainsi que le concept de Lehmann sur le temps et l'espace métonymiques. Mots-clés: Théâtre Contemporain. Théâtre Postdramatique. Processus de Création. Analyse de Compagnie. Génétique de la Performance. 


\section{A Trajetória da Pan Pan Theatre}

A Pan Pan Theatre é uma companhia teatral com sede em Dublin, fundada em 1991 por Aedín Cosgrove, designer de iluminação e cenógrafo, e Gavin Quinn, diretor artístico. A companhia foi criada depois que ambos se formaram no Trinity College Dublin (TCD), Cosgrove em Teatro e História da Arte e Quinn em Teatro e Estudos Clássicos. Mais tarde na sua carreira, e também no TCD, Cosgrove tornou-se mestre em Sistemas Multimídia, em 2000. A simbiose entre diretor e designer produziu uma companhia teatral sem precedentes na Irlanda, e talvez tenha sido exatamente essa falta de referências em seu próprio país que os motivou a criar as suas próprias referências. Desde seu início eles já criaram vinte e cinco peças de teatro e performances, fizeram turnês pelo mundo e receberam vários prêmios nacionais e internacionais.

O impulso inicial para fundar a companhia foi uma criação teatral que estivesse mais ligada à estética continental europeia, em oposição à tradição de textos dramáticos que predominavam nos palcos irlandeses no início dos anos 1990. Com efeito, no contexto irlandês da prática teatral e performance contemporâneas, a Pan Pan Theatre é uma das companhias pioneiras na criação de trabalhos originais fora dos moldes dramáticos, sempre buscando desafiar não apenas as convençóes, mas também suas próprias abordagens no fazer teatral. Desse modo, a companhia vem, ao longo de vinte e dois anos, desenvolvendo um estilo muito próprio. Sua investigação constante das possíveis linguagens da performance é ilustrada pelo ecletismo de seus projetos, que variam em forma, conteúdo e abordagem. De adaptaçôes, ou respostas a textos canônicos como Macbeth (MACBETH 7, 2004'), Hamlet (The Rehearsal. Playing the Dane, 2010²) e King Lear (Everybody is King Lear in his own home, 2012), a criaçóes interdisciplinares como ONE: Healing with Theatre $(2005)^{3}$, que começou como um projeto fotográfico, evoluiu para um documentário e, finalmente, tornou-se uma performance/instalação. Além disso, $O N E$ foi publicada em forma de livro e exibida como um filme com a duração de 14 horas. Da mesma forma, a produção multipremiada da peça para a rádio de Beckett, All That Fall $\left(2011^{4}\right)$, definida em seu website como "uma composição multicamadas de vozes que pode ser experimentada como uma comédia de humor negro, um mistério de assassinato, um enigma literário ou uma partitura quase musical, mas que é melhor aproveitada ao ser experienciada na atmosfera única 
da sala de espetáculos da Pan Pan, que é perfeitamente ajustada às suas apresentações teatrais ${ }^{5}$.

Apesar dessa diversidade, de acordo com sua estética pessoal, mas ainda em desenvolvimento, todos os projetos são movidos pelo mesmo princípio: o foco na experiência do público através da criação de uma atmosfera específica, juntamente com um estilo de performance muito particular. Seu ímpeto experimental foi inicialmente inspirado pela arte conceitual e pelos movimentos de vanguarda europeus do início do século XX. Atualmente, podemos incluir a Pan Pan Theatre na categoria abrangente da estética pós-dramática desenvolvida por Hans-Thies Lehmann, que nos oferece ferramentas críticas específicas do âmbito teatral que facilitam a discussáo analítica e teórica sobre o teatro e a performance contemporâneos.

Este artigo pensa a estética da Pan Pan Theatre por intermédio de uma instância de seu processo de ensaio, em especial trata-se de analisar o tipo de performance do grupo, que não pode ser dissociado de sua intenção de criar uma atmosfera específica. Com relação ao estilo de atuação, Quinn busca uma qualidade multifacetada que se encontra no continuum de Michael Kirby entre a performance não-matricial e a atuação complexa (Zarrilli, 2002). Em relação à atmosfera, esse estilo de performance reforça sua concepção particular de tempo e espaço como metonímica, isto é, "[...] não primariamente definida como um substituto simbólico de outro mundo fictício", mas tratada "[...] como parte e continuação do espaço teatral real" (Lehmann, 2006, p. 151). Sua dramaturgia visual reforça essa metonímia ao estabelecer uma lógica própria que desafia o mundo real e o mundo da ficção, operando em uma área liminoide.

\section{A Estética da Pan Pan Theatre}

A estética da Pan Pan Thetre pode ser vista como parte do amplo leque de possibilidades do teatro pós-moderno, como a crítica do The Irish Times, Sarah Keating, rotulou seu último show Everybody is King Lear in his own home, que estreou no Dublin Theatre Festival em setembro de $2012^{6}$. Não se pode negar que o uso que a Pan Pan Theatre faz de estratégias pós-modernas, tais como fragmentação, intertextualidade, autorreferencialidade, pastiche, paródia, etc., tornou-se parte de seu estilo distinto, especialmente suas respostas desconstruídas a textos canônicos como Macbeth, Hamlet e King Lear. Entretanto, pode ser mais proveitoso analisar isso através do 
prisma da estética pós-dramática, que nos dá um aparato mais rico para examinarmos as particularidades do teatro e da performance contemporâneos.

O Tipo de Performance da Pan Pan como Parte Integral de sua Estética Metonímica de Espaço e de Tempo

É final de março de 2012 e essa é a fase final dos ensaios da Pan Pan Theatre para a contemporizaçáo de Casa de Bonecas. Gavin Quinn, diretor artístico e cofundador da companhia, dá instruçóes a um dos atores: "[...] sinta o espaço, sinta a energia no espaço, absorva o público, faça um leve contato visual com eles, sentindo sua energia. Não se apresse a dar o texto, tome seu tempo, apenas esteja lá, sem pressa para falar" (Ruiz, 2012, s. p.). O ator parece confuso e pouco convencido, mas ele faz uma vez mais sua entrada, tentando incorporar as instruçóes de Quinn.

Esse episódio tem sido recorrente em todo o processo de ensaio com alguns atores do elenco. Ao considerar que a maioria dos atores foram capazes de alcançar até certo ponto o nível de performance que Quinn busca nos atores com quem trabalha, esse ator em particular parece incapaz de compreender o estilo ou o tipo que em última análise se relaciona à Pan Pan Theatre. As implicaçôes são várias, mas, primariamente, isso compromete a visão de Quinn e, também, resulta em negligência com outros atores, uma vez que Quinn precisa gastar mais tempo polindo a abordagem desse ator específico com seu personagem até o ponto em que ele acha aceitável. Na sala de ensaios tensões surgem na medida em que a fase de produção se aproxima.

A resistência do ator à visão de Quinn traz os problemas relativos à protoperformance para o primeiro plano, especificamente o treinamento formal e informal e a experiência. Nesse sentido, vale lembrar que aquilo que Phillip B. Zarrilli defende em sua introdução a Acting (Re)Considered, isto é, que os atores encarnam "[...] teorias e práticas específicas da atuaçáo localizável dentro de um conjunto de circunstâncias históricas, socioculturais e estéticas/dramatúrgicas. Da mesma forma, gêneros têm teorias e práticas de atuação que são como elas histórica e contextualmente específicas" (Zarrilli, 2002, p. 3). Nesse caso em particular, o ator pertence à tradição do realismo psicológico surgido após Stanislavski no mundo ocidental ${ }^{7}$, e que predomina no contexto irlandês no qual o teatro ainda é amplamente associado à forma dramática. 
Quinn também está lidando com uma questão maior, que tem a ver com a teoria substantiva: "[...] ideias pré-concebidas e pontos de vista que propõem a atuação como uma verdade (isto é, um sistema, discurso ou prática)" (Zarrilli, 2002, p. 3). Esses pressupostos, muitas vezes, impedem que os atores (e o público) permaneçam imparciais às novas abordagens contemporâneas da performance teatral. Por isso, como Robert Gordon explica em The Purpose of Playing. Modern Acting Theories in Perspective:

[...] os problemas surgem quando, no decorrer de suas carreiras profissionais, os atores são convidados a criar performances usando convençóes técnicas e cênicas diferentes daquelas nas quais foram treinados. Esses problemas não surgem simplesmente por que os atores não estão familiarizados com convençôes e técnicas estranhas, mas também porque sua identidade performática já foi formada pela estética que eles absorveram sem autoconsciência em seu treinamento (Gordon, 2006, p. 3).

A afirmação de Gordon pode, sem dúvida, ser, também, aplicada ao público acostumado a consumir um tipo específico de produto em certos contextos. Nesse sentido, as produçóes da Pan Pan Theatre têm sido desafiadoras tanto para o público irlandês quanto para os atores desde o seu primeiro espetáculo, em 1991, Negative Act, escrito e dirigido por Quinn. Sua estreia foi no Lombard Street Studio Theatre em Dublin ${ }^{8}$ e, mais tarde, no mesmo ano, apresentado no Lyon International Student Festival, na França. Quinn descreve Negative Act como uma peça

[...] sobre a ideia da ausência de linguagem, que era uma noção muito abstrata sobre quatro personagens, na qual um escrevia continuamente longe dos outros três. O título Negative Act vem da noção de não fazer nada, a ideia do nada, logo a peça em si era sobre o nada. Apenas usando o tempo no palco e tratando da criação de uma linguagem a partir do nada; a peça era bastante abstrata e conceitual, oferecia poucas palavras e era essencialmente aquilo que poderíamos chamar de experimental (Quinn, 2011, s. p.).

Desde então, a companhia tem desenvolvido um estilo de performance/atuação único, que Ben Bratley, em sua crítica no The New York Times em 2008 sobre a produçáo Oedipus Loves You, comparou com as produçóes de Lars von Trier, "[...] com um estilo de atuação basicamente inexpressivo que lembra o movimento cinematográfico Dogma 95"9. Entretanto, o que Quinn está tentando atingir é muito multifacetado e se encontra no continuum de Michael Kirby entre a performance não-matricial e a atuação complexa (Zarrilli, 2002). 
A atuação complexa no estilo performático da Pan Pan Theatre é necessária para se apresentar - e não representar - o mundo fictício, enquanto a performance não-matricial é necessária para se criar tempo e espaço metonímicos. A performance não-matricial é entendida por Kirby em relação aos Happenings: "[...] embora a atuação fosse às vezes utilizada, nos Happenings os performers geralmente tendiam a 'ser' nada ou ninguém senão eles mesmos; eles também não representavam, ou fingiam estar, em um tempo ou lugar diferentes do espectador" (Zarrilli, 2002, p. 40). A combinação de ambos os extremos do continuum traz o mundo fictício para o espaço do evento ao vivo, ao autorreflexivamente reconhecer-se como uma performance, isto é, como um encontro no aqui e agora com o público. A performance não-matricial é necessária como uma estratégia dramatúrgica para transformar "o nível da realidade explicitamente em um 'companheiro de jogo" (Lehmann, 2006, p. 100), com o objetivo de produzir uma certa indecidibilidade entre a realidade e a ficção. A Pan Pan Theatre reforça esse efeito ao obscurecer os limites entre o tempo da performance e o tempo fictício, isto é, o tempo da performance é intencionalmente usado como tempo dramático.

Simultaneamente, seguindo estratégias pós-modernas, o ator/ performer torna-se mais um elemento a serviço do lugar - aqui compreendido como tempo e espaço -, e, assim, outro aspecto da linguagem teatral do palco juntamente com o texto e a cenografia. Desse modo, como Gordon afirma, a Pan Pan Theatre usa "[...] a tendência pós-moderna para 'misturar e combinar' formas e técnicas da performance" (Gordon, 2006, p. 7). Consequentemente, a estética da Pan Pan Theatre responde a várias camadas que podem ser localizadas nos paradigmas da classificação de Kirby, assim como dentro da noção sobrecarregada da presença, e a ideia de presentificação pós-dramática ${ }^{10}$, definida por Lehmann como "[...] uma experiência intencionalmente não-mediada do real (tempo, espaço, corpo) (Lehmann, 2006, p. 134).

Em termos de presença, no nível da atuação complexa, a estética da Pan Pan Theatre pode ser localizada naquilo que Thomas Whitaker identificou como "[...] o círculo de consciência expandida no teatro, fluindo do ator para o espectador e vice-versa, que sustenta o mundo dramático" (Fuchs, 1996, p. 70). Isso quer dizer, nas palavras de Josette Féral, que o ator é o "produtor de teatralidade e o canal através do qual ela passa” (2002, p. 94) para o público. Essa 
consciência expandida também é buscada por abordagens fenomenológicas dos métodos de atuaçáo que concebem o corpo como um veículo de energia, que pode ser treinado através das técnicas de "via negativa" (Barba, 1991, p. 18), assim como as de Jerzy Grotowski, Peter Brook, Eugenio Barba, Jacques Lecoq ou Anne Bogart e Tadashi Suzuki. Em última análise, o objetivo é enfatizar uma conexão entre o performer e o público. Seguindo Artaud, Gordon rotula essas abordagens - apesar de suas diferenças - como terceiro teatro "[...] por defender uma estética de performance como presença" (Gordon, 2006, p. 275).

No nível da performance não-matricial, a ideia de presença se enquadra na tendência pós-dramática na qual o ator "[...] muitas vezes náo é mais um ator de um papel mas um performer oferecendo sua presença no palco para a contemplação" (Lehmann, 2006, p. 135). A autorreferencialidade e a autorreflexividade, ao apropriar-se da performance artística, ocorrem não por que elas apontam exclusivamente para a presença (e para a ausência) do performer, como nas estratégias pós-modernas, mas também para o performer como parte do evento em uma "[...] consciência contínua dele próprio como performance, e na indisponibilidade dessa performance para a re/ apresentação" (Fuchs, 1996, p. 79).

Esses são, de fato, conceitos que não são facilmente transmissíveis para o ator. Problemas de comunicação e técnicas de direção surgem. Apesar de seu estilo muito específico de performance Quinn não usa nenhuma técnica para guiar seus atores, tais como os View Points de Bogart, que poderiam funcionar bem na obtenção da abordagem contemporânea de Quinn com relação à presença de palco de atores que não estão acostumados a métodos de atuação fisicamente extenuantes. Assim, ele só pode transmitir conceitualmente seu estilo poligonal de performance para os performers. Isso sugere que ele depende completamente das habilidades do ator e acredita que um ator profissional deveria ter adquirido através da protoperformance seus próprios recursos para transmitir o que é exigido dele. Isto é, seu treinamento profissional e experiência deveriam ter fornecido a ele as ferramentas necessárias para enfrentar as diferentes abordagens do fazer teatral. Portanto, a Pan Pan Theatre requer grande habilidade dos atores para manter todas essas camadas em equilíbrio, o que, em última análise, tira partido da estética da companhia que busca criar atmosferas através de um forte senso de tempo e espaço metonímicos. 
Além disso, o objetivo de sua abordagem é, em última instância, o de formar uma conexão com o público, incluindo os espectadores como parte do evento performático e, ao mesmo tempo, trazendo-os para o mundo do espetáculo. Como Lehmann argumenta "[...] a estética da distância do espectador é um fenômeno do teatro dramático; nas novas formas de teatro que estão mais próximas da performance essa distância é estruturalmente abalada" (2006, p. 104). Normalmente isso é feito através da quebra da quarta parede, mas no caso da Pan Pan Theatre há uma sutileza a mais, uma vez que isso é conseguido através da transformação do público em cúmplices do mundo fictício. Isso é conseguido com os atores fazendo contato visual com o público de modos diferentes e sutis. Às vezes eles trocam olhares com os espectadores, como se estivessem interrogando-os sobre o que está sendo apresentado no palco, ou como se esperassem que o público desse a eles uma resposta para um problema específico. Outras vezes, o sentimento é o de que diálogos são filtrados pelo público, como se ele estivesse reconhecendo que, em última análise, é a percepção do espectador na plateia que no final das contas dá significado para a situação que acontece no palco. Usualmente, eles olham para um espectador específico, como se estivessem tentando adivinhar seus pensamentos; ou, ocasionalmente, simplesmente tentam criar uma conexão que torna explícita para o público, isto é, os torna conscientes da realidade da performance em si, do fato de que ela é apresentada ao vivo, do ato de observar e ser observado. Os espectadores são, então, forçados a criar seus próprios significados, não apenas no sentido do que os performers estão realmente tentando comunicar através do que não é dito, mas apresentada a eles, como também sendo forçados a reconhecer seu próprio papel dentro da performance. Lehmann classifica essa abordagem como "[...] a produção de situações para o auto interrogação, a auto exploração e a autoconsciência de todos os participantes. [...] ocorre uma reversáo do ato artístico em direçáo aos espectadores" (Lehmann, 2006, p. 105). Consequentemente, com esse tipo específico de performance que se move rapidamente entre planos diferentes, o público precisa estar consciente de seus processos de criação de sentido. Assim como os atores, alguns espectadores aprendem e sentem prazer com essas convenções, enquanto outros resistem a elas.

Quinn explica esse tipo de trabalho como um meio pelo qual a performance pode ser concretizada pelo público: 
[...] nós sempre enfatizamos o público, a maneira como podemos ser claros com o público, como podemos estabelecer e reestabelecer aquele contato, e como podemos ter uma boa atmosfera entre o público e essa troca de energias interessante. Trata-se de completar, de ser completado pelo público (Quinn, 2011, s. p.).

O estilo visual da Pan Pan Theatre, seu uso dos espaços e da cenografia, trabalham em simbiose com o estilo de performance buscado pela Pan Pan Theatre, tornando-se - assim como o público - um colaborador no processo de criaçáo de sentido. $\mathrm{O}$ conceito subjacente é a criação de um mundo, mas não de acordo com estruturas simétricas; essa não é uma "[...] dramaturgia organizada de maneira exclusivamente visual, mas uma dramaturgia que não está subordinada ao texto, podendo, portanto, desenvolver livremente sua própria lógica" (Lehmann, 2006, p. 93).

Às vezes essa dramaturgia visual é propositalmente falha, permitindo uma falta de ocultação no palco, no qual os atores mudam de figurino, manipulam a iluminação ou corajosamente mostram ao público os truques e táticas do jogo teatral: "o triunfo da teatralidade sobre o ilusionismo" (White, 2009, p. 146). Isso é reforçado ainda mais pelo uso de elementos como adereços que, às vezes, parecem arbitrários e outras vezes são usados semioticamente e, como um ideograma, expressam a ideia de algo sem referir-se diretamente a ele, algo ao qual Quinn refere-se como pós-semiótica. Por exemplo, em The Rehearsal. Playing the Dane, golas e velas vitorianas foram usadas como referência de uma era, coexistindo com enormes latóes de metal. Com seu senso de humor paródico, uma insinuação para o duplo sentido de Dane ${ }^{11}$ como o cáo de raça foi teatralizado com a presença de um cáo dinamarquês de verdade no palco e uma enorme faixa com sua fotografia pendurada no centro, que também servia como anúncio do espetáculo.

A esse respeito, deve-se dizer que, tematicamente, a Pan Pan Theatre normalmente explora os lugares mais escuros e solitários da mente humana, e suas consequentes disfunçóes sociais e pessoais se manifestam em ambientes quiméricos. No entanto, esses são retratados com uma combinaçáo de humor e seriedade, jocosidade e perversidade, que também são características de seu estilo único. 


\section{O Tempo Real como Tempo Dramático: misturando o real e o fictício}

O uso do tempo está intrinsecamente relacionado ao tipo de performance da Pan Pan Theatre, já que "[...] o teatro é classicamente uma forma de arte baseada no uso do tempo" (Quinn, 2011, s. p.). Essa "realidade física e sensual da experiência do tempo" (Lehmann, 2006, p. 153) deve ser compreendida dentro de certos parâmetros: "[...] ela é uma questão de execução de atos que são reais no aqui e agora e que se realizam no próprio momento em que acontecem" (Lehmann, 2006, p. 104), herdado dos Happenings e da estética da performance artística, e isso está no cerne da ideia de se completar tarefas no palco. Esta última é uma estratégia usada frequentemente por muitos profissionais do teatro contemporâneo para garantir que os atores se concentrem em açóes no palco que náo respondem a motivaçóes psicológicas ou objetivas e são realizadas com uma espontaneidade que busca a qualidade de improvisação, isto é, uma imprevisibilidade que tenta atingir o realismo no palco, em oposição à repetição ensaiada.

No caso da Pan Pan Theatre, como vimos, através da performance náo-matricial dos atores a vivacidade se torna um objeto de experiência, isto é, "[...] o tempo como uma experiência compartilhada por todos, constitui o centro de um novo tempo dramático" (Lehmann, 2006, p. 155), ao transformar o tempo real em tempo dramático, obscurecendo as fronteiras com o tempo da ficção. De modo semelhante, no palco os atores são responsáveis por seu próprio uso do tempo, durante a performance, de acordo com o seu próprio senso de momento específico em termos de público, colegas e energia pessoal. Eles não improvisam exatamente, mas reagem à energia produzida pelo encontro arbitrário com o público, à transitoriedade e vivacidade de cada performance. Além disso, o tempo real também é incorporado à dramaturgia, tornando-se o tempo da performance ao invés de um tempo representado ou ficcional. Ao considerar que há referências ao tempo ficcional no texto falado, a mise-en-scène desafia essas referências ao apresentar uma continuidade da ação no palco. Até mesmo entradas e saídas, que são raras no trabalho da Pan Pan Theatre, náo são usadas de forma tradicional para demarcar uma mudança na ação, na cena, no espaço ou no tempo. Elas sáo antes usadas para levar a atmosfera para um novo nível ou dimensão. Isso pode produzir tanto uma sensação de atemporalidade quanto de 
ocasióes múltiplas dentro do mesmo espaço de tempo. Quinn explica esse uso do tempo como portas dramáticas para dimensôes diferentes: "[...] isso significa que você pode de repente mudar, mover-se, fluir para uma nova ideia sem ter que construir todos os tijolos do edifício ao longo do caminho" (Quinn, 2011, s. p.).

Em suas produçôes isso pode dar uma sensação de desconexão entre as açôes, e arbitrariedade na atuação/performance. Isso é feito através de interrupçôes: por exemplo, uma estratégia comum usada pela Pan Pan Theatre é romper a ação dos performers de modo súbito, tocando música ao vivo no palco; ou mudando radicalmente o ritmo. Em suma, a estética da Pan Pan Theatre exemplifica a ruptura que o teatro pós-dramático apresenta:

[...] intermedialidade, a civilização das imagens e o ceticismo para com as grandes teorias e metanarrativas dissolvem a hierarquia que anteriormente haviam garantido não apenas a sujeição de todos os meios teatrais ao texto mas também a coerência entre eles. [...] Ao invés disso o teatro assume um caráter fragmentário e parcial. Ele renuncia aos critérios há muito incontestáveis de unidade e síntese e abandona a si próprio ao acaso (e ao risco) de confiar em impulsos individuais, fragmentos e microestruturas de textos para tornar-se um novo tipo de prática (Lehmann, 2006, p. 56-57).

Assim, para Quinn, o uso da quarta dimensão relaciona-se simultaneamente ao estilo da performance e à dramaturgia, e transforma tanto o tempo quanto o espaço da performance em metonímica. Assim, o mundo fictício não é deixado para trás, mas há uma interação constante entre o mundo da peça e o mundo da performance. Quinn busca integrar ambos os mundos, e é através dessa concepção particular de tempo e tipo de performance que essa integração ocorre, unindo o real e o fictício através da movimentação rápida, mas sutil entre a performance não-matricial e a atuação complexa. É importante compreender isso como integração e não como disjunção entre o personagem e o ator, como no caso de Brecht. Os performers não demonstram personagens, mas movem-se com fluidez entre sua persona performática e o personagem. Embora o efeito seja similar ao de Brecht, inevitavelmente a desfamiliarização ou estranhamento ocorre. Nesses termos, talvez o que Quinn busque seja invalidar o deslocamento pós-moderno da presença e ausência em termos de ator/performer e personagem, como explicado por Simon Shepherd e Mick Wallis: 
[...] na sua tentativa de capturar a problemática do pósmodernismo em 1977, Benamou chegou à conclusão de que não devemos escolher entre Presença e Ausência; estamos no império da indecidibilidade entre categorias e sua desconstrução (Benamou, 1977, p. 5). Ao mesmo tempo, é uma observação comum dizer que o teatro decreta uma circulação entre a presença do ator e a ausência da pessoa representada; e a ausência da pessoa do ator em seu papel (Shepherd; Wallis, 2006, p. 235).

Além disso, Quinn desafia as noçóes de presença no nível metafísico tanto do dualismo cartesiano quanto daquele que Zarrilli chama de "uma noção subjetivista reificada de "presença" (2002, p. 15). Ambos assumem uma essência transcendental, uma ideia platônica de uma entidade fixa que eventualmente constitui o ser em oposição a uma construção performativa em fluxo. Ademais, nenhuma das posiçóes é capaz de integrar uma à outra, isto é, "integrar a mente no corpo e o corpo na mente" (Zarrilli, 2002, p. 15).

$\mathrm{O}$ argumento é comprovado na sala de ensaios da Pan Pan Theatre com sua última produção Everybody is King Lear in their own home, na qual ambos os atores envolveram-se em conversas conceituais e teóricas contribuindo com muitas decisóes dramáticas com seu conhecimento. Ao mesmo tempo, eles foram capazes de traduzir de forma criativa a abordagem conceitual de Quinn do ensaio através da improvisação. Problemas de comunicação não apareceram devido à protoperformance dos atores. Nesse sentido, pode-se dizer que não apenas a prática precisa infundir teoria, mas também os novos campos de pesquisa acadêmica como a Genética da Performance, a Análise do Fazer Teatral Contemporâneo e os Processos Criativos e de Ensaio tentam fazer, como também escolas de atuação deveriam incluir certos paradigmas teóricos para dar aos atores as habilidades necessárias para compreender as diferentes exigências que um mercado cada vez mais competitivo requer no mundo do teatro. 


\section{Notas}

${ }^{1}$ Indicado ao prêmio de melhor iluminação, Irish Times Theatre Awards 2004.

${ }^{2}$ Irish Times Theatre Awards, prêmio de melhor produçáo e melhor design em 2010.

${ }^{3}$ Indicado ao prêmio especial do júri, Irish Times Theatre Awards 2006.

${ }^{4}$ Melhor design de som e melhor iluminação, Irish Times Theatre Awards 2011.

${ }^{5}$ Disponível em: <http://panpantheatre.com/shows/all-that-fall/>. Acesso em: 21 fev. 2013.

${ }^{6}$ Disponível em: <http://irishtimes.com/newspaper/features/2012/1003/1224324769237. html>. Acesso em: 20 fev. 2013.

${ }^{7}$ Os problemas com o chamado Método, em relação ao legado de Stanislavski, têm sido discutidos em detalhe por muitos, tanto em termos de concepçóes errôneas de suas teorias, devido à má tradução de seu livro canônico An Actor Prepares, que lidou com o aspecto psicológico de seu sistema, quanto com a separaçáo do seu segundo tomo, que trata do mundo físico envolvido com o desenvolvimento de um personagem (Ver, por exemplo, Merlin; Hern, 2007).

${ }^{8}$ Agora reaberto como Green On Red Galleries.

${ }^{9}$ Disponível em: <http://theater.nytimes.com/2008/05/24/theater/reviews/24oedi.html>. Acesso em: 20 fev. 2013.

${ }^{10}$ Mas que não é localizada no continuum da performance artística e live art como autoapresentação, que é pós-moderna, e, paradoxalmente, ao apontar para si mesma, ao invés de descentralizar o ator/performer, coloca a sua presença/ausência no epicentro através da autorreferencialidade/autorreflexividade.

${ }^{11}$ N.T.: em inglês: dinamarquês.

\section{Referências}

BARBA, Eugenio (Org.); GROTOWSKI, Jerzy. Towards a Poor Theatre. London: Methuen Drama, 1991.

BRANTLEY, Ben. From Thebes to Suburbia, in Dire Need of Therapy. New York Times, Nova York, 24 maio 2008. Disponível em: <http://theater.nytimes.com/2008/05/24/ theater/reviews/24oedi.html>. Acesso em: 20 fev. 2013.

FÉRAL, Josette. Theatricality: the specifity of theatrical language. SubStance \#98/99, v. 31, n. 2-3, p. 94-108, 2002.

FUCHS, Elinor. The Death of Character. Perspectives on Theater after Modernism. Indianapolis: Indiana University Press, 1996.

GORDON, Robert. The Purpose of Playing. Modern Acting Theories in Perspective. Ann Arbor: University of Michigan Press, 2006.

GROTOWSKI, Jerzy. Towards a Poor Theatre. London: Methuen Drama, 1991.

KIRBY, Michael. On Acting and Not-Actin. In: ZARRILLI, Phillip (Org.). Acting (Re) 
Considered. A Theoretical and Practical Guide. London/New York: Routledge, 2002. P. 40-52.

LEHMANN, Hans-Thies. Postdramatic Theatre. Oxon/New York: Routledge, 2006.

MERLIN, Bella. The Complete Stanislavski's Toolkit. London: Nick Hern Books, 2007.

QUINN, Gavin. Entrevista concedida a Noelia Ruiz (texto digitado) em 14 jun. 2011.

RUIZ, Noelia. Rehearsal Notes. Março 2012.

SHEPHERD, Simon; WALLIS, Mick. Drama/Theatre/Performance. Oxon/New York: Routledge, 2006.

WHITE, Christine (Org.). Directors and Designers. Bristol/Chicago: Intellect, 2009.

ZARRILLI, Phillip (Org.). Acting (Re)Considered. A Theoretical and Practical Guide. London/New York: Routledge, 2002.

Noelia Ruiz é mestre e doutora em Teatro pela University College Dublin - UCD, na Irlanda. Atualmente, trabalha na área de teatro na Irlanda e na Inglaterra.

E-mail: noelia.ruiz@ucdconnect.ie

Traduzido do original em inglês por Martin Heuser. Revisado por Marcelo de Andrade Pereira.

Recebido em 23 de fevereiro de 2013 Aprovado em 20 de abril de 2013 